\title{
BMJ Open Willingness to pay per quality-adjusted life year for life-saving treatments in Thailand
}

\author{
Khachapon Nimdet, ${ }^{1}$ Surachat Ngorsuraches ${ }^{2}$
}

To cite: Nimdet K, Ngorsuraches S. Willingness to pay per quality-adjusted life year for life-saving treatments in Thailand. BMJ Open 2015;5:e008123. doi:10.1136/bmjopen-2015008123

- Prepublication history for this paper is available online To view these files please visit the journal online (http://dx.doi.org/10.1136/ bmjopen-2015-008123).

Received 6 March 2015 Revised 25 August 2015 Accepted 7 September 2015

\section{(a) CrossMark}

${ }^{1}$ Faculty of Pharmaceutical Sciences, Prince of Songkla University, Hatyai, Songkhla, Thailand

${ }^{2}$ College of Pharmacy, South Dakota State University,

Brookings, SD, USA

Correspondence to Dr Surachat Ngorsuraches; surachat.ngorsuraches@ sdstate.edu

\section{ABSTRACT}

Objective: To estimate the willingness to pay (WTP) per quality-adjusted life year (QALY) value for lifesaving treatments and to determine factors affecting the WTP per QALY value.

Design: A cross-sectional survey with multistage sampling and face-to-face interviews.

Setting: General population in the southern part of Thailand.

Participants: A total of 600 individuals were included in the study. Only $554(92.3 \%)$ responses were usable for data analyses.

Outcome measure: Participants were asked for the maximum amount of WTP value for life-saving treatments by an open-ended question. EQ-5D-3L and visual analogue scale (VAS) were used to estimate additional QALY.

Results: The amount of WTP values varied from 0 to 720000 Baht/year (approximately 32 Baht=US\$1). The averages of additional QALY obtained from VAS and $E Q-5 D-3 L$ were only slightly different $(0.872$ and 0.853 , respectively). The averages of WTP per QALY obtained from VAS and EQ-5D-3L were 244720 and 243120 Baht/QALY, respectively. As compared to male participants, female participants were more likely to pay less for an additional QALY ( $p=0.007)$. In addition, participants with higher household incomes tended to have higher WTP per QALY values $(p<0.001)$.

Conclusions: Our study added another WTP per QALY value specifically for life-saving treatments, which would complement the current costeffectiveness threshold used in Thailand and optimise patient access to innovative treatments or technologies.

\section{INTRODUCTION}

Increasing health expenditures has been an important problem around the globe. ${ }^{12}$ In Thailand, total health expenditures were 367767 million Baht in 2008, an increase from 127655 million Baht in 1994. It was approximately $4 \%$ of the country's gross domestic product (GDP) and rose due to various reasons, for example, innovations. ${ }^{3}$ The Thai government is responsible for two of three major health insurance schemes,

\section{Strengths and limitations of this study}

- This study used legitimate hypothetical health scenarios, for example, targeted health state, along with a rescaling utility measure, to improve the method for examining WTP per QALY value for life-saving treatments in Thailand.

- The study provided evidence that a simple approach might work for examining the WTP per QALY value for setting cost-effectiveness (CE) threshold for life-saving technologies. It supports the concept of using a flexible CE threshold, which indicates that a single CE threshold for all technologies is not appropriate.

- Study results can be generalised to only a specific Thai population.

which cover almost $90 \%$ of overall population. ${ }^{4}$ Therefore, the government needs to efficiently allocate resources. ${ }^{56}$

It has been widely accepted that economic evaluation, for example, cost-effectiveness analysis (CEA) and cost-utility analysis (CUA), is an important decision-making tool for healthcare resource allocation. ${ }^{7}$ Economic evaluation compares costs and benefits between competing technologies as incremental cost-effectiveness ratio (ICER) or incremental cost-utility ratio (ICUR) ${ }^{8}{ }^{9} \mathrm{~A}$ common measure of trading off between costs and benefits is incremental cost per quality-adjusted life year (QALY) gained. ${ }^{10} \mathrm{In}$ general, as long as a technology has additional costs for additional benefits, it requires a cost-effectiveness threshold (CE threshold) to determine whether it is costeffective or not. ${ }^{11-13}$

CE thresholds have been stated implicitly or explicitly and vary across jurisdictions, for example, they are US\$50 000 per QALY in the USA, ${ }^{14}$ \$C20 000-100 000 per QALY in Canada ${ }^{15}$ and $£ 20000-30000$ per QALY in the UK. ${ }^{16}$ There is no single standard method for valuing $\mathrm{CE}$ threshold. It could be derived from several methods including WHO 
recommendations, a human capital approach, expert opinion and willingness to pay (WTP) ${ }^{17-19}$ However, there have been studies examining WTP per QALY and using it to verify the CE threshold value used in each individual country, for example, the USA, Denmark, Australia, South Korea, Taiwan and Thailand. ${ }^{20-33}$ A stated preference method, contingent valuation (CV), has been used to elicit WTP per QALY in several studies because it can generate hypothetical scenarios based on diseases or health status. For example, King et $a l^{26}$ used a visual analogue scale (VAS), standard gamble (SG) and time trade-off (TTO) for utility measurement, and used an iterative closed-ended bidding method to determine WTP per QALY for moving from current health state to perfect health state, and Shiroiwa $e t a l^{23}$ used bid values in double-bound dichotomous choice to determine WTP per QALY for an additional 1 year of survival with perfect health status.

In Thailand, the CE threshold was previously implicitly set as one to three times GDP per capita, based on WHO recommendations. ${ }^{19}$ Recently, the commissioners of health technology assessment recommended $<1.2$ times the per capita gross national income (GNI) (160 000 Baht) for the CE threshold. ${ }^{34}$ There are two studies examining WTP per QALY to verify CE threshold in the country. Thavorncharoensap et $a l^{24}$ estimated WTP per QALY in 2008 by using a bidding game technique for WTP measures and using TTO and VAS for utility measures in moving from various health conditions, including blindness, paralysis and allergy for 5 years as hypothetical scenarios to current health state. Later, Thavorncharoensap $e t a l^{85}$ used a double-bounded dichotomous choice method followed by open-ended questions to examine WTP for moving from three major health states including treatment scenario, life extension and life-saving situation, to either full health or an extension of life for various durations, which produced 0.2 and 0.4 QALY gained. The study results confirmed the legitimacy of the currently used CE threshold in the country.

However, according to the current CE threshold, a number of technologies and programmes are not costeffective. Some cases were controversial since they were generally cost-effective in other countries. For instance, once-in-a-lifetime population-based mammographic screening for women aged either 40-49 or 50-59 years was determined as not cost-effective or did not have good value for money in Thailand. ${ }^{36}$ Similarly, in the case of new technologies or treatments for lifethreatening diseases, since they are potentially not costeffective, patients would have limited access to them. It would be interesting to specifically examine the WTP per QALY value for these types of disease. Therefore, the objectives of this study were to estimate WTP per QALY value for life-saving treatments and to determine factors affecting the WTP per QALY value. This study was part of a larger project that used another method to elicit WTP per QALY.
METHODS

\section{Questionnaire development}

We used a questionnaire survey as a tool to collect data in this study. It was composed of three parts, including utility measurement, WTP measurement and demographic questions. Since EQ-5D-3L and VAS are easily understood and administered, we used them to measure utility or an additional QALY that an individual gained from moving between two health scenarios, which were a health state with life-threatening disease and current health state. The EQ-5D-3L was composed of five dimensions: mobility, self-care, usual activities, pain or discomfort and anxiety or depression. Each dimension has three levels including no problems, some problems and extreme problems. ${ }^{37} 38$ Participants were asked to choose levels of all dimensions. For VAS, we used a 0 100 unit 'thermometer-type' scale, where 0 and 100 were labelled 'dead' and 'perfect health', respectively. ${ }^{37}$ Participants were asked to evaluate health states on three thermometer-type scales, consisting of perfect health state, dead state and current health state, consecutively. They marked only one point at first and second scales as warm-up exercises. On the third scale, we asked them to mark the three points of perfect health state, dead state and current health state.

We used a single question, 'Please imagine that you have had a life-threatening disease for 1 year. If you do not receive treatment you will die today. On the other hand, there is a treatment that can help you get back to your current health state but you can only live for one more year (in the current health state) and then die. What is the maximum value would you be willing to pay per month for that treatment for 1 year?', to determine WTP. In addition, the trained interviewers asked respondents to review the scenario and question to check their understanding, and emphasised that the amount of payment should be under that they would be able to pay. If they did not want to pay, we asked them for their reasons. In the questionnaire, we also asked for participants' gender, residential area, age, education, health scheme, marital status, number of family members, individual income, household income and diseases that they currently had.

We asked three experts to review the questionnaire to check content validity and we made a revision accordingly. To ensure the validity of the questionnaire, we carried out three rounds of interviews with 10 conveniently sampled participants each and adjusted the questionnaire. We then piloted it with 30 participants residing in Songkhla province and found that they clearly understood the questions, and could imagine the hypothetical scenarios included in the questionnaire.

\section{Data collection}

The National Statistical Office of Thailand calculated sample size and selected respondents representing the population of southern Thailand targeted for our study, where we could reach out using limited resources. 
All provinces were classified by average household income and a stratified multistage cluster random sampling technique was used to identify areas and households. We finally needed to conduct face-to-face interviews with a total of 600 individuals residing in three provinces including Surat Thani, Pattalung and Satun. The data collection period in December 2013 and ended in February 2014. We had seven trained interviewers in this study. After the interviews, we provided a token of appreciation to the interviewers as well as to participants.

\section{Data analysis}

All analyses were performed using SPSS V.18.0 for Windows (Chicago, Illinois, USA). We descriptively analysed demographic data. We used EQ-5D-Thai tariff to calculate utility scores of all current health states. ${ }^{38}$ The marked points of the third thermometer-type scale were used to calculate the current health state utility of participants. Some respondents did not correctly mark the perfect health state and death state on the scale at 100 and 0 , respectively. Therefore, rescaling was necessary in calculating utility of current health state depending on each individual. ${ }^{39}$ The rescaling formula is shown below,

$$
\begin{aligned}
& \text { VAS }_{\text {current health state-rescaled }} \\
& =\frac{\text { VAS }_{\text {current health state-raw }}-\text { Death }_{\text {raw }}}{{ }^{\prime} 11111_{\text {raw }}^{\prime}-\text { Death }_{\text {raw }}}
\end{aligned}
$$

where VAS $_{\text {current heath state-rescaled is the utility of rescaled }}$ current health state, VAS $_{\text {current health state-raw is the score }}$ of current health state, Death ${ }_{\text {raw }}$ is the score of death and ' 11111 ' raw is the score of perfect health state.

We calculated WTP per QALY value from the ratio of WTP value for saving their lives from death due to lifethreatening disease to current health states and the additional QALY. All data of unwillingness to pay values were transformed to zero and included in calculation. The additional QALY was derived from the difference of utilities between death due to life-threatening disease $(\mathrm{u}=0.000)$ and current health state of each individual. Specifically, we used the following formula to calculate WTP per QALY for each respondent.

$$
\text { WTP per QALY }=\frac{12 \times \mathrm{WTP} / \text { month }}{\mathrm{U}_{\text {current health state }}-\mathrm{U}_{\text {death }}}
$$

where WTP per QALY is the WTP per QALY value, WTP/month is the amount of WTP (Baht) per month, $\mathrm{U}_{\text {current health state }}$ is the utility of current health state and $\mathrm{U}_{\text {death }}$ is the utility of death due to life-threatening disease. We calculated the average WTP per QALY values from each individual WTP per QALY.

Finally, we performed multiple linear regression analysis to examine the factors affecting WTP per QALY values. We transformed the WTP per QALY values derived from the rescaled VAS to $\log$ scale and used them as dependent variables, and used demographic variables as independent variables, in this analysis.

\section{RESULTS}

\section{Demographic data}

A total of $554(92.3 \%)$ responses were usable for data analyses. While $38(6.3 \%)$ participants did not understand how to mark on VAS for the three health states, 5 $(0.8 \%)$ participants could not imagine the hypothetical scenarios and $3(0.5 \%)$ participants could not indicate the maximum payment for the treatment of lifethreatening disease. Table 1 shows the characteristics of participants. The average age of participants was 41.4 years. The number of female participants was a little more than male participants. The majority (62.8\%) lived in rural areas. Most participants had a secondary school degree $(39 \%)$ and were married $(74.2 \%)$. The averages of individual income and household income were approximately 13000 and $30000 \mathrm{Baht} / \mathrm{month}$, respectively.

\section{WTP and WTP per QALY}

Table 2 shows WTP values, additional QALYs and WTP per QALY values. A total of 534 participants were willing

\begin{tabular}{|c|c|}
\hline Characteristics & $N=554$ \\
\hline Average age $\pm S D$ (years) & $41.4 \pm 12.4$ \\
\hline \multicolumn{2}{|l|}{ Gender, N (\%) } \\
\hline Female & $298(53.8)$ \\
\hline Male & $256(46.2)$ \\
\hline \multicolumn{2}{|l|}{ Province, N (\%) } \\
\hline Surat Thani & $299(54.0)$ \\
\hline Pattalung & 165 (29.8) \\
\hline Satun & $90(16.2)$ \\
\hline \multicolumn{2}{|l|}{ Area, N (\%) } \\
\hline Urban & $206(37.2)$ \\
\hline Rural & $348(62.8)$ \\
\hline \multicolumn{2}{|l|}{ Education, N (\%) } \\
\hline Primary school & $181(32.7)$ \\
\hline Secondary school & $216(39.0)$ \\
\hline Bachelor or higher education & $157(28.3)$ \\
\hline \multicolumn{2}{|l|}{ Marital status, $\mathrm{N}(\%)$} \\
\hline Single or divorce & $143(25.8)$ \\
\hline Married & $411(74.2)$ \\
\hline \multicolumn{2}{|l|}{ Health scheme, N (\%) } \\
\hline Universal cover & $367(68.7)$ \\
\hline Non-universal coverage & 167 (31.3) \\
\hline \multicolumn{2}{|l|}{ Average income $\pm S D$ (Baht/month) } \\
\hline Individual & $13194 \pm 10078$ \\
\hline Household & $30003 \pm 28501$ \\
\hline \multicolumn{2}{|l|}{ Average current utility $\pm S D$} \\
\hline Rescaled visual analogue scale & $0.872 \pm 0.140$ \\
\hline EQ-5D-3L Thai tariff & $0.853 \pm 0.163$ \\
\hline
\end{tabular}
to pay for life-saving treatments. Twenty (3.6\%) participants were unwilling to pay. These included 13 
Table 2 Additional QALYs, WTP values and WTP per QALY values

\begin{tabular}{lcl}
\hline & $\begin{array}{l}\text { Average } \\
\text { (N=554) }\end{array}$ & $\begin{array}{l}\text { Minimum- } \\
\text { maximum }\end{array}$ \\
\hline WTP (Baht/year) & $\begin{array}{c}206825 \pm 388837 \\
0.872 \pm 0.140\end{array}$ & $\begin{array}{l}0-720000 \\
0.100-1.000\end{array}$ \\
$\begin{array}{l}\text { Additional QALY } \\
\text { using VAS }\end{array}$ & $0.853 \pm 0.163$ & $0.513-1.000$ \\
$\begin{array}{l}\text { Additional QALY } \\
\text { using EQ-5D-3L }\end{array}$ & $244720 \pm 489398$ & $0-8640000$ \\
WTP (Baht) per & & \\
QALY using VAS & $243120 \pm 409652$ & $0-7200000$ \\
WTP (Baht) per & & \\
$\begin{array}{l}\text { QALY using } \\
\text { EQ-5D-3L }\end{array}$ & & \\
\hline $\begin{array}{l}\text { QALY, quality-adjusted life year; VAS, visual analogue scale; } \\
\text { WTP, willingness to pay. }\end{array}$ &
\end{tabular}

participants who could not afford to and seven participants who believed the Thai government should support the cost of treatments. We found that WTP values for life-saving treatments varied from 0 to 720000 Baht/ year (approximately $32 \mathrm{Baht}=\mathrm{US} \$ 1$ ). The averages of additional QALY obtained by VAS and EQ-5D-3L were only slightly different ( 0.872 and 0.853 , respectively) and the averages of WTP per QALY from both utility measurement methods were also similar (244720 and 243120 Baht/QALY, respectively).

\section{Factors affecting WTP per QALY values}

WTP per QALY values had positively skewed distribution and were transformed to $\log$ (WTP per QALY). Before analysis, we excluded responses from three participants who had outlier WTP per QALY values since they might lead to biased results. Table 3 shows the results of multiple regression analysis for factors affecting the WTP per QALY values. Multiple linear regression analysis built a significant model $\left(\mathrm{F}=8.432, \quad \mathrm{R}^{2}=0.121\right.$, degree of freedom $=8, \quad \mathrm{p}<0.001)$. Only gender and household income were statistically significant factors associated with the WTP per QALY values. As compared to male participants, female participants significantly had lower WTP per QALY values $(p=0.007)$. In addition, participants with higher household incomes tended to have higher WTP per QALY values $(\mathrm{p}<0.001)$.

\section{DISCUSSION}

The study results showed that participants were willing to pay approximately 240000 Baht for an additional QALY in cases of saving their lives from death due to life-threatening disease to current health states. This amount was 1.42 times Thailand GDP per capita, or 1.80 times GNI per capita, which was still lower than the highest CE threshold recommended by the WHO (three GDP per capita), and 1.50 times the implicit CE threshold (160 $000 \mathrm{Baht} / \mathrm{QALY}$ or 1.2 times of GNI per capita) currently used in Thailand. ${ }^{34}$ Interestingly, the WTP per QALY values derived from this study were in line with WTP per QALY for unilateral blindness treatment, but lower than WTP per QALY for a life-saving condition, which were derived from two previous studies in the country (285000 and 334045 Baht/QALY, respectively). ${ }^{24} 35$

Table 3 Factors affecting WTP per QALY values

\begin{tabular}{|c|c|c|c|c|c|}
\hline Variable & $\mathbf{N}$ & $\begin{array}{l}\text { Average WTP per } \\
\text { QALY } \pm S D(B a h t / Q A L Y)\end{array}$ & Coefficient* & SE & p Value \\
\hline Intercept & - & - & 5.074 & 0.096 & $<0.001 \dagger$ \\
\hline Age & - & - & -0.002 & 0.001 & 0.276 \\
\hline \multicolumn{6}{|l|}{ Gender } \\
\hline Male (ref) & 232 & $194648 \pm 152678$ & - & - & - \\
\hline Female & 266 & $168947 \pm 150796$ & -0.084 & 0.031 & $0.007 \dagger$ \\
\hline \multicolumn{6}{|l|}{ Area } \\
\hline Urban (ref) & 183 & $190581 \pm 157203$ & - & - & - \\
\hline Rural & 315 & $175308 \pm 148966$ & -0.035 & 0.033 & 0.296 \\
\hline \multicolumn{6}{|l|}{ Education } \\
\hline Primary school & 166 & $162120 \pm 144572$ & - & - & - \\
\hline Secondary school & 196 & $181025 \pm 155135$ & 0.037 & 0.038 & 0.331 \\
\hline Bachelor or higher & 136 & $203716 \pm 154477$ & 0.011 & 0.048 & 0.812 \\
\hline \multicolumn{6}{|l|}{ Marriage status } \\
\hline Single/divorce (ref) & 143 & $187529 \pm 151118$ & - & - & - \\
\hline Married & 388 & $178437 \pm 152554$ & 0.018 & 0.037 & 0.621 \\
\hline \multicolumn{6}{|l|}{ Health scheme } \\
\hline Universal coverage (ref) & 339 & $172124 \pm 150521$ & - & - & - \\
\hline Non-universal coverage & 159 & $199673 \pm 142111$ & 0.053 & 0.037 & 0.148 \\
\hline Household income & - & - & $5.591 \times 10^{-6}$ & 0.00 & $<0.001 \dagger$ \\
\hline
\end{tabular}


Different concepts and methods might be main reasons for the discrepancies between these WTP per QALY values. For instance, CE threshold recommended by the WHO and CE threshold currently used in Thailand were both based on income, while the results from two previous studies in the country were based on preference. ${ }^{24}{ }^{35}$ However, the diseases used among these studies were also different. The first study examined the WTP for three diseases, including unilateral/bilateral blindness, paraplegia/quadriplegia and mild/moderate allergies, while another study used three situations, treatment, life extension and life saving, to determine the WTP per QALY values. ${ }^{24}{ }^{35}$ In our study, we only used a life-threatening disease. In addition, outcomes of treatment were set differently. For instance, one of the previous studies asked participants for their WTP for a treatment that could return them from blindness to current health state, ${ }^{24}$ while another study asked participants for their WTP for a treatment that could bring them back from a serious disease to full health. ${ }^{35}$ However, the participants in this study considered their WTP for a treatment that could move them back from death due to a non-specific serious disease to their current health state. Also, generally asking participants to imagine recovery from a disease to current health state should be more legitimate than moving from lifethreatening disease back to full health, as used in a previous study. ${ }^{35}$ Therefore, although this study showed that the WTP per QALY derived from death due to a serious disease moving to the current health states for 1 year was lower than the WTP per QALY derived from immediate death due to a serious disease moving to the full health state for 2 months (334 045 Baht/QALY), as used in one of the previous studies, ${ }^{35}$ these types of study results might not be a proper comparison.

Another reason for the different WTP per QALY values could be from the different WTP elicitation methods used among these preference-based studies. Although the advantages of using an open-ended question in this study were that it was easier to understand and it required a short time for interviews, one of the disadvantages was that it was difficult to answer, as compared to other techniques such as closed-end or bidding, and it could usually lead to low response rates. ${ }^{40}$ Therefore, the open-ended question could be the reason explaining lower WTP per QALY in this study, as compared to other WTP per QALY values derived from life saving and life extension used in previous study. ${ }^{24} 35$

We also found that the amount of payment was approximately $70 \%$ of household income. This result was consistent with the results from previous studies. In general, respondents would express maximum WTP for life saving or life extension. ${ }^{41-43}$ For instance, Pennington et $a t^{43}$ found that deriving a WTP for a QALY from coma and terminal scenarios generated higher values than those from other scenarios. One of the reasons would be that this type of scenario is likely to depress marginal utility of income, and money might be worthless to individuals under these circumstances. Therefore, it was possible that respondents in this study fully recognised life-saving treatments and might have thought of other financial resources, for example, household income and bank deposits, and selling their properties, to pay for the treatments.

On the contrary, 20 respondents in this study were unwilling to pay for saving their lives in the hypothetical scenario. We found that their household incomes varied widely from 5000 to $110000 \mathrm{Baht} / \mathrm{month}$. Therefore, the reasons for their unwillingness to pay could be that they could not really afford to or they intentionally did not want to pay if they were in that state of health. Also, from the question estimating WTP in this study, the average WTP was derived from only 1 year of treatment. WTP might change in different durations. ${ }^{23}$ Therefore, it limits the generalisability of the results.

Interestingly, all preference-based study results, including this study, revealed that the WTP per QALY was higher than the current CE threshold used in Thailand. Although this was important information, and reflected public opinion, it was not meant to be the best justification for any single ceiling $\mathrm{CE}$ threshold. Instead, the results supported using flexible $\mathrm{CE}$ thresholds for different health conditions. ${ }^{31} 4445$ In fact, some countries have already adopted flexible CE thresholds, for example, the Netherland has a specific CE threshold for treatments of life-threatening diseases. ${ }^{46}$

Another intuitive result was that the household income of participants was a statistically significant factor affecting the WTP per QALY value. Participants who had higher incomes were willing to pay more for an additional QALY. This result was consistent with the findings in a previous study. ${ }^{24}$ It was also consistent with the data that we found in 12 of 20 participants who expressed unwillingness to pay for treatments of life-threatening diseases, they had low income. Although education level was not a significant factor in this study, as it was in a previous study, participants with higher education levels tended to have higher WTP per QALY. Moreover, male participants were willing to pay more than female participants, 49713 Baht/QALY on average. This result was consistent with a previous study's result. ${ }^{24}$

The results of this study added two important elements to the WTP per QALY literature for Thailand. First, they revealed the WTP per QALY for moving away from a health state with life-threatening disease to current health state, instead of full health, as in the most recent study, which is not usually the case in reality. Second, this study showed evidence that using a simple hypothetical question to determine the WTP per QALY might work in the same manner as using sophisticated utility and WTP measures, as seen in previous studies, since the WTP per QALY was not greatly different as long as the initial and ended health states were the same or similar. Those investigators used a lot of resources to determine the WTP per QALY, and were always 
concerned about the participants' comprehension of included scenarios. If there is more evidence that using simple hypothetical scenarios works well, it will allow more opportunity for researchers or policymakers to use different $\mathrm{CE}$ thresholds for economic evaluation of different technologies.

There were two main limitations in this study. First, the participants did not represent the entire Thai population, which might include different socioeconomic characteristics. We needed to carefully generalise the results. For instance, the average household income of our participants and that in the general Thai population in 2013 were different (approximately 30000 and 19000 Baht/month, respectively). ${ }^{47}$ Second, we estimated the WTP per QALY value using only one life-threatening disease scenario. The WTP per QALY in this study should not be used in other situations. Instead, valuing WTP per QALY from different hypothetical scenarios should be estimated in future studies.

\section{CONCLUSIONS}

Health technology assessment is the norm for allocation of healthcare resources in Thailand. CE threshold is essential when upcoming competing technologies have greater effectiveness and higher cost than present technologies. It also has an impact on patient access to new technologies. Our study added another WTP per QALY value specifically for life-saving treatments, complementing the current CE threshold used in the country and helping to optimise patient access to treatments or technologies.

Contributors KN conducted all analyses, wrote the first draft of the manuscript and collected the data. SN designed the study, planned the analyses, and edited the manuscript. Both authors read and approved the final manuscript.

Funding This study was granted by Health Insurance System Research Office, Thailand, and the Faculty of Pharmaceutical Sciences, Prince of Songkla University.

\section{Competing interests None declared.}

Patient consent Obtained

Ethics approval Faculty of Pharmaceutical Sciences, Prince of Songkla University Ethics Committee.

Provenance and peer review Not commissioned; externally peer reviewed.

Data sharing statement No additional data are available.

Open Access This is an Open Access article distributed in accordance with the Creative Commons Attribution Non Commercial (CC BY-NC 4.0) license, which permits others to distribute, remix, adapt, build upon this work noncommercially, and license their derivative works on different terms, provided the original work is properly cited and the use is non-commercial. See: http:// creativecommons.org/licenses/by-nc/4.0/

\section{REFERENCES}

1. World Health Organization. World health statistic. 2011. http://www. who.int/whosis/whostat/EN WHS2011 Full.pdf (accessed 4 Apr 2011)
2. Organization for Economic Co-Operation and Development. Health at a Glance. 2009. http://www.oecd-ilibrary.org/content/book/health glance-2009-en (accessed 4 Nov 2010).

3. International Health Policy Program. National health accounts of Thailand 2002-2008. http://ihpp.thaigov.net/nha_reports/Final\% 20Report\%20of\%20Thai-NHa\%202008_revise.pdf (accessed 13 Jan 2013).

4. Jirawattanapisal T, Kingkaew P, Lee TJ, et al. Evidence-based decision-making in Asia-Pacific with rapidly changing health-care systems: Thailand, South Korea, and Taiwan. Value Health 2009;12 (Suppl 3):S4-11.

5. Ngorsuraches S, Meng W, Kim BY, et al. Drug reimbursement decision-making in Thailand, China, and South Korea. Value Health 2012;15(1 Suppl):S120-5.

6. Tanvejsilp P, Ngorsuraches S. Defining the scope of health technology assessment and types of health economic evaluation $J$ Med Assoc Thai 2014;97(Suppl 5):S10-16.

7. McLaughlin N, Ong MK, Tabbush V, et al. Contemporary health care economics: an overview. Neurosurg Focus 2014;37:E2.

8. Liljas B, Lindgren B. On individual preferences and aggregation in economic evaluation in healthcare. Pharmacoeconomics 2001;19:323-35.

9. Wasserfallen JB, Krieg MA, Greiner RA, et al. Cost effectiveness and cost utility of risedronate for osteoporosis treatment and fracture prevention in women: a Swiss perspective. J Med Econ 2008;11:499-523.

10. Gyrd-Hansen D. Willingness to pay for a QALY: theoretical and methodological issues. Pharmacoeconomics 2005;23:423-32.

11. Weinstein MC, Zeckhauser RJ. Critical ratios and efficient allocation. $J$ Public Econ 1973;2:147-57.

12. Gafni A, Birch S. Incremental cost-effectiveness ratios (ICERs): the silence of the lambda. Soc Sci Med 2006;62:2091-100.

13. Sendi P. Bridging the gap between health and non-health investments: moving from cost-effectiveness analysis to a return on investment approach across sectors of economy. Int $J$ Health Care Finance Econ 2008;8:113-21.

14. Weinstein MC. How much are Americans willing to pay for a quality-adjusted life year? Med Care 2008;46:343-5.

15. Laupacis A, Feeny D, Detsky AS, et al. How attractive does a new technology have to be to warrant adoption and utilization? Tentative guidelines for using clinical and economic evaluations. CMAJ 1992;146:473-81.

16. McCabe C, Claxton K, Culyer AJ. The NICE cost-effectiveness threshold: what it is and what that means. Pharmacoeconomics 2008;26:733-44.

17. Grosse SD. Assessing cost-effectiveness in healthcare: history of the $\$ 50,000$ per QALY threshold. Expert Rev Pharmacoecon Outcomes Res 2008;8:165-78.

18. Hirth RA, Chernew ME, Miller E, et al. Willingness to pay for a quality-adjusted life year: in search of a standard. Med Decis Making 2000;20:332-42.

19. World Health Organization. Macroeconomics and health: investing in health for economic development. Report of the WHO Commission on Macroeconomics and Health, World Health Organization, Geneva, Switzerland:, 2001.

20. Gyrd-Hansen D. Willingness to pay for a QALY. Health Econ 2003;12:1049-60.

21. Pinto-Prades JL, Sanchez-Martinez Fl, Corbacho B, et al. Valuing QALYs at the end of life. Soc Sci Med 2014;113:5-14.

22. Robinson A, Gyrd-Hansen D, Bacon P, et al. Estimating a WTP-based value of a QALY: the 'chained' approach. Soc Sci Med 2013:92:92-104.

23. Shiroiwa T, Sung YK, Fukuda T, et al. International survey on willingness-to-pay (WTP) for one additional QALY gained: what is the threshold of cost effectiveness? Health Econ 2010;19: 422-37.

24. Thavorncharoensap M, Teerawattananon $\mathrm{Y}$, Natanant S, et al. Estimating the willingness to pay for a quality-adjusted life year in Thailand: does the context of health gain matter? Clinicoecon Outcomes Res 2013:5:29-36.

25. Byrne MM, O'Malley K, Suarez-Almazor ME. Willingness to pay per quality-adjusted life year in a study of knee osteoarthritis. Med Decis Making 2005;25:655-66.

26. King JT Jr, Tsevat J, Lave JR, et al. Willingness to pay for a quality-adjusted life year: implications for societal health care resource allocation. Med Decis Making 2005;25:667-77.

27. Lieu TA, Ray GT, Ortega-Sanchez IR, et al. Willingness to pay for a QALY based on community member and patient preferences for temporary health states associated with herpes zoster. Pharmacoeconomics 2009;27:1005-16.

28. Martin-Fernández J, Polentinos-Castro E, del Cura-Gonzalez MI, et al. Willingness to pay for a quality-adjusted life year: an evaluation 
of attitudes towards risk and preferences. BMC Health Serv Res 2014; $14: 287$.

29. Pinto-Prades JL, Loomes G, Brey R. Trying to estimate a monetary value for the QALY. J Health Econ 2009;28:553-62.

30. Richardson J, lezzi A, Sinha K, et al. An instrument for measuring the social willingness to pay for health state improvement. Health Econ 2014:23:792-805.

31. Shiroiwa T, Igarashi A, Fukuda T, et al. WTP for a QALY and health states: more money for severer health states? Cost Eff Resour Alloc 2013;11:22.

32. Zethraeus N. Willingness to pay for hormone replacement therapy. Health Econ 1998;7:31-8.

33. Zhao FL, Yue $\mathrm{M}$, Yang $\mathrm{H}$, et al. Willingness to pay per quality adjusted life-year: is one threshold applicable for all decision-making? Value Health 2010;13:A538.

34. National List of Essential Medicines Committee. Sub-committee of Thai Working Group on Health Technology Assessment 2013 meeting report of 2 nd annual meeting.

35. Thavorncharoensap M, Leelahavarong P, Doungthipsirkul S, et al. Preliminary results "Assessing a societal value for a ceiling threshold in Thailand". 2013. http://www.hitap.net (accessed 9 Jul 2013).

36. Chalkidou K, Marquez P, Dhillon PK, et al. Evidence-informed frameworks for cost-effective cancer care and prevention in low, middle, and high-income countries. Lancet Oncol 2014;15:e119-31.

37. EuroQoL. EQ-5D-3L User Guide version 4.0: basic information on how to use the EQ-5D-3L instrument [online]. http://www.eurogol. org/fileadmin/user_upload/Documenten/PDF/Folders_Flyers/ UserGuide_EQ-5D-3L-pdf (accessed 7 Dec 2010).
38. Sakthong P. Measurement of clinical-effect: utility. J Med Assoc Thai 2008;91(Suppl 2):S43-52.

39. Szende A, Oppe M, Devlin N. EQ-5D value sets: inventory, comparative review and user guide. Dordrecht: Springer, 2007.

40. Bateman IJ, Carson RT, Day B, et al. Economic valuation with stated preference techniques. Edward Elgar: Cheltenham, 2002.

41. Nimdet K, Chaiyakunapruk N, Vichansavakul K, et al. A systematic review of studies eliciting willingness-to-pay per quality-adjusted life year: does it justify CE threshold? PLOS ONE 2015;10: e0122760.

42. Ryen L, Svensson M. The willingness to pay for a quality adjusted life year: a review of the empirical literature. Health Econ 2014;24:1289-301.

43. Pennington M, Baker R, Brouwer W, et al. Comparing WTP values of different types of QALY gain elicited from the general public. Health Econ 2015;24:280-93.

44. Institute for Health and Clinical Excellence. Guide to the methods of technology appraisal. 2013. http://www.nice.org.uk/Article/PMG9/ chapter/the-reference-case (accessed 10 Dec 2014).

45. Gyrd-Hansen D, Kjaer T. Disentangling WTP per QALY data: different analytical approaches, different answers. Health Econ 2012;21:222-37.

46. Boersma C, Broere A, Postma MJ. Quantification of the potential impact of cost-effectiveness thresholds on Dutch drug expenditures using retrospective analysis. Value Health 2010;13:853-6.

47. National Statistical Office. Household income 1993-2013. http:// service.nso.go.th/nso/web/statseries/statseries11.html (accessed 16 Feb 2015). 